\section{Development of a Nutrient Film Technique Culture System for Arbuscular Mycorrhizal Plants}

Yun-Jeong Lee ${ }^{1}$

Institute of Plant Nutrition (330), Hohenheim University, Fruwirthstr. 20, 70593 Stuttgart, Germany \& National Institute of Agricultural Science and Technology, RDA, Suwon, 441-707, Republic of Korea

Eckhard George ${ }^{2}$

Leibniz Institute of Vegetable and Ornamental Crops, 14979 Grossbeeren, Germany \& Plant Nutrition Institute of Crop Sciences, Humboldt University Berlin, 10115 Berlin, Germany

Additional index words. arbuscular mycorrhiza, lettuce, inoculum production, mycorrhizal plant production, NFT system

Abstract. A nutrient film technique (NFT) culture system was developed to allow nursery production of arbuscular mycorrhizal horticultural crops. This would benefit horticultural production and allow for uncomplicated production of mycorrhizal hyphae. Roots of lettuce (Lactuca sativa var. capitata) plants were highly colonized by the arbuscular mycorrhizal fungus, Glomus mosseae (BEG 107) after 4 weeks in the NFT system, following an initial phase of five weeks in inoculated in Perlite substrate. In the NFT system, a thin layer of glass beads was used to provide solid support for plant and fungus growth and nutrient solution was supplied intermittently (15 min, six times per day). A modified nutrient solution $(80 \mu \mathrm{M})$ was used and was replaced with fresh solution every 3 days. A significantly higher dry weight was found for the mycorrhizal versus the nonmycorrhizal lettuce plants in Perlite during the precolonization period. The root colonization rate was also high at rates up to $80 \mu \mathrm{M}$ P supply. On the NFT system, growth differences between mycorrhizal and nonmycorrhizal plants were less than in Perlite. However, root colonization rate was not reduced during the NFT culture period. In this system, high amounts of fungal biomass were produced. This would allow the determination of metal and other nutrient concentrations in fungal hyphae. Furthermore, we found large amounts of external fungal hyphae surrounding the root surface. As much as $130 \mathrm{mg}$ fungal biomass were collected per culture plate (three plants). Therefore, we suggest that this modified NFT culture system would be suitable for fungal biomass production on a large scale with a view to additional aeration by intermittent nutrient supply, optimum Psupply, and a use of glass beads as support materials. Furthermore, bulk inoculum composition with a mixture of spores, colonized roots, and hyphae grown in soilless media by the modified NFT system might be a useful way to massproduce mycorrhizal crops and inoculum for commercial horticultural purposes.

Most studies of mycorrhizal plants have been conducted in soil. However, the collection of clear fungal hyphae for determination of nutrient concentration is impossible in soil culture since hyphae of AM cannot be fully separated from the soil. It has been reported that some cultures in nutrient solution, such as hydroponics, aeroponics and nutrient flow culture have various advantages in this respect.

1) Soilless culture provides soilless preparations of mycorrhizal material.

2) Rates of nutrient supply at the root surface can be manipulated easily.

Received for publication 16 Apr. 2004. Accepted for publication 22 Aug. 2004. This research was partly financed by the Ministry of Education \& Human Resources Development of Republic of Korea and the Deutsche Forschungsgemeinschaft(DFG), grant no. GE 920/4.

${ }^{1}$ Plant nutritionist and corresponding author. Current address: Division of Organic Farming Technology, National Institute of Agricultural Science and Technology, RDA, Suwon, 441-707, Republic of Korea; e-mail yjlee@rda.go.kr.

${ }^{2}$ Professor.
3) Substrate-free spores and colonized roots can be collected for various uses such as taxonomic identification of the fungus, production of inoculum and molecular studies (Hawkins and George, 1998).

Mycorrhizal plants have been cultured in hydroponics (Dugassa, 1995; Hawkins and George, 1999; Peuss, 1958), aeroponics (Hung and Sylvia, 1988; Mohammad et al., 2000; Sylvia and Hubbel, 1986) and in a nutrient flow system (Mosse and Thompson, 1984). Aeroponic culture of mycorrhizal plants has been experimentally used in nurseries (Jarstfer and Sylvia, 1995). Nutrient film technique, which is now widely used in commercial horticultural crop production, was pioneered by Cooper (1975) and more fully described by Winsor et al. (1979). The plant roots lie in a shallow layer of rapidly flowing nutrient solution and as root mats develop, the upper layers above the liquid retain a film of moisture around them. Therefore, this system may provide the fungus with enough air and nutrient solution without disturbing hyphal growth.

The aim of these experiments was to establishment of a nutrient film technique (NFT) culture system for the AM plants, that is, G. mosseae lettuce plants. It was considered that this system might enable the direct investigation of metal cations uptake by mycorrhizal hyphae and their transport to lettuce. Also, the possibility of using this system for mass production of mycorrhizal horticultural crops under greenhouse conditions was evaluated.

\section{Materials and Methods}

Two experiments were conducted. The first experiment was a trial to determine in Perlite substrate the optimum $P$ concentration of the nutrient solution to avoid reduction of plant growth while maintaining an adequate root colonization rate. The second experiment tested whether the modified NFT could be used for the commercial production of mycorrhizal crop plants under greenhouse conditions.

Plant and fungus culture: Expt. 1. Seeds were pregerminated overnight in saturated $\mathrm{CaSO}_{4}$ and sowed directly into $150-\mathrm{mL}$ pots (thinned to one plant per pot after emergence) containing Perlite and soil-based BEG 107 inoculum ( $10 \%$ of pot volume) or Perlite and inoculum filtrate (Blue Ribbon filter paper no. 5893; Schleicher \& Schüll, Dassel, Germany) and grown for 5 weeks. Perlite (1 to $3 \mathrm{~mm}$ ) was prepared by washing with tap water over a 1-mm mesh sieve, sun-drying, and then heat treating for $24 \mathrm{~h}$ at $110{ }^{\circ} \mathrm{C}$. Perlite was mixed uniformly either with the inoculum (for mycorrhizal plants) or the inoculum filtrate and same amount of sterilized inoculum (for nonmycorrhizal plants). Plants in pots were irrigated daily with $40 \mathrm{~mL}$ nutrient solution with different $\mathrm{P}$ concentration $10 \mu \mathrm{M}, 40 \mu \mathrm{M}$, and 80 $\mu \mathrm{M}$ one or two times per day (see below for the composition of nutrient solution), respectively. After five weeks, the dry weight and percentage colonized root was determined.

Plant and fungus culture: Expt. 2. Plants in Perlite, which had been colonized by AM after 5 weeks using a rate of $80 \mu \mathrm{M} \mathrm{P}$, were transplanted into the NFT system to be cultivated for another 4 weeks. In the NFT system, P was supplied at a concentration of $80 \mu \mathrm{M}$ P. To transplant, the pots were submerged in deionized water, the roots carefully separated from the Perlite, and the plants placed into the NFT system plate (Plexiglas material, $15 \times 45$ $\mathrm{cm}$, three plants per plate). In the NFT plate, glass beads were used as thin layer (about 1 cm thickness) to provide solid support for plant and fungus growth. The roots were placed on the glass bead layer and fixed in black plastic foil, which was carefully laid to cover the entire plate. The percentage colonized root was determined again at the time of harvest. The fungal hyphae were collected from the glass beads in NFT plate for the determination of fungal biomass. The extraradical hyphal mats surrounded with lettuce roots were excluded for the determintion of fungal biomass because it could not be separated completely from the root. After separation of plant root from the glass beads layer, all of grass beads were collected in a beaker $(5 \mathrm{~L})$ and then rinsed with deionized water four times. The fungal 
Table 1. Total root colonization and shoot fresh weights of mycorrhizal lettuce plant after 5 weeks of precolonization in Perlite. Different letters indicate statistical difference due to $\mathrm{P}$ supply $(P<0.05$, one-way ANOVA). Data are means of four replications $\pm \mathrm{SE}$.

\begin{tabular}{lccc}
\hline P supply $(\mu \mathrm{M})$ & 10 & 40 & 80 \\
\hline Colonization rate $(\%)$ & $58.7 \pm 2.1 \mathrm{a}$ & $86.3 \pm 4.2 \mathrm{~b}$ & $77.5 \pm 3.9 \mathrm{~b}$ \\
Shoot fresh weight $(\mathrm{g})$ & $13.94 \pm 0.61 \mathrm{a}$ & $19.00 \pm 2.12 \mathrm{~b}$ & $23.95 \pm 1.80 \mathrm{~b}$ \\
\hline
\end{tabular}

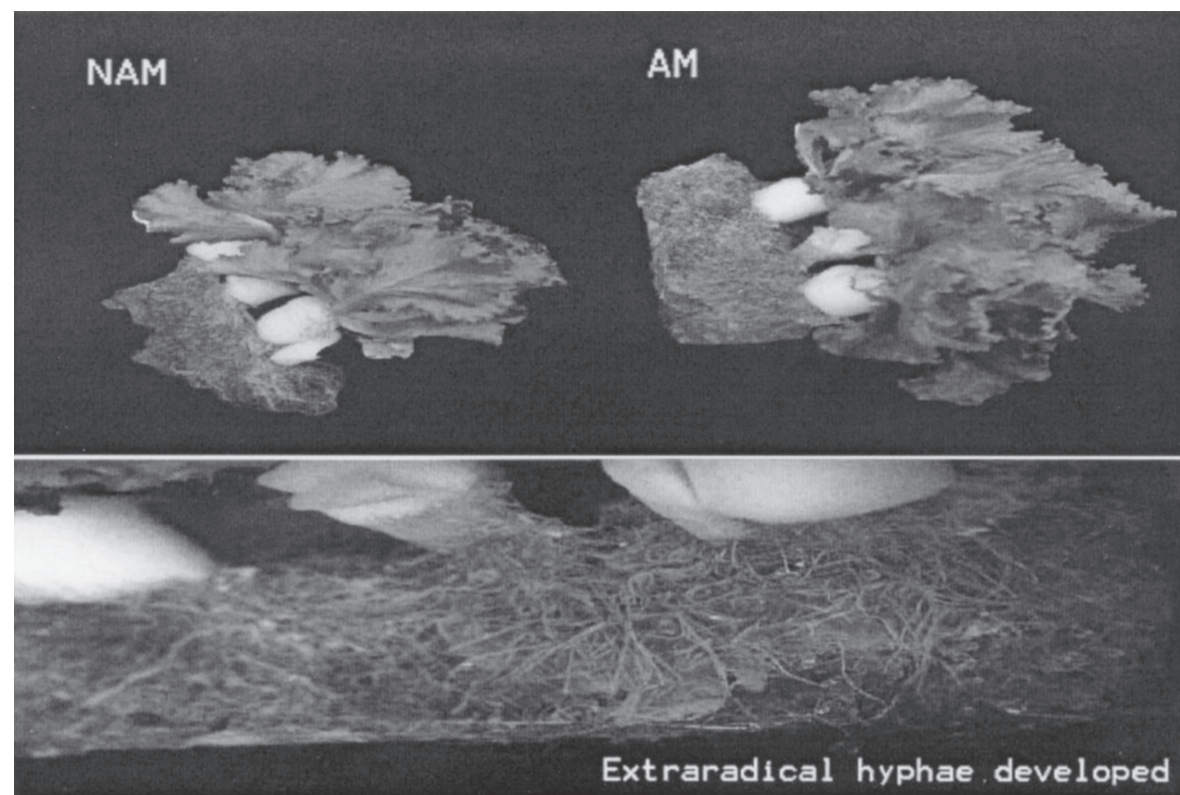

Fig. 1. Root development of nonmycorrhizal (NAM) and mycorrhizal (AM) lettuce plants and external hyphae developed in NFT system at harvest.

hyphae in supernatant were collected using sieve (30 $\mu \mathrm{m}$ pore size). After rinsing the fungal hyphae on the sieve carefully with double distilled water, fungal hyphae were collected into Eppendorf tube and dried at 50 ${ }^{\circ} \mathrm{C}$ in an oven for $2 \mathrm{~d}$ to determine dry weights. Shoot and roots were harvested for dry weight determination after sampling the fresh $\operatorname{root}(0.5$ $\mathrm{g}$ fresh weight per plant) for the determination of mycorrhizal colonization. Shoot and roots sampled were dried at $70^{\circ} \mathrm{C}$ in an oven for three days and thereafter determined dry weights. The experiments were carried out in a growth chamber with a PAR of 400 to 500 $\mu \mathrm{mol} \cdot \mathrm{m}^{-2} \cdot \mathrm{s}^{-1}$ (mercury halide lamps, Osram Powerstar HQI-T-2000 W/D), a day/night temperature of $25 / 20^{\circ} \mathrm{C}$ and a relative humidity of about $60 \%$.

Nutrient media. The plants in Perlite culture were supplied with $1 / 10$ strength nutrient solution for the first $4 \mathrm{~d}$ in all experiments and thereafter with a full strength of nutrient solution, which consisted of the following macronutrients (mM): $\mathrm{Ca}\left(\mathrm{NO}_{3}\right)_{2} 4 \mathrm{H}_{2} \mathrm{O}(2), \mathrm{KH}_{2} \mathrm{PO}_{4}$ $\mathrm{H}_{2} \mathrm{O}(0.0752), \mathrm{K}_{2} \mathrm{HPO}_{4} 2 \mathrm{H}_{2} \mathrm{O}(0.0048), \mathrm{K}_{2}^{2} \mathrm{SO}_{4}$ $(0.7), \mathrm{KCl}(0.1), \mathrm{MgSO}_{4} 7 \mathrm{H}_{2} \mathrm{O}(0.5)$ and micronutrients $(\mu \mathrm{M}): \mathrm{H}_{3} \mathrm{BO}_{3}(10), \mathrm{MnSO}_{4} \mathrm{H}_{2} \mathrm{O}$ (3), $\mathrm{ZnSO}_{4} 7 \mathrm{H}_{2} \mathrm{O}(0.5), \mathrm{CuSO}_{4} 5 \mathrm{H}_{2} \mathrm{O}(0.2)$, $\left(\mathrm{NH}_{4}\right)_{6} \mathrm{Mo}_{7} \mathrm{O}_{24} 4 \mathrm{H}_{2} \mathrm{O}(0.01), \mathrm{FeEDTA}^{2}$ (10). A $\mathrm{pH}$ of 6.0 was maintained by $0.15 \mathrm{~mm}$ MES$\mathrm{KOH}$. The nutrient solutions was circulated and replaced every $3 \mathrm{~d}$. The nutrient solution was supplied by water pump, which connected to a time switch so as to supply nutrient solution for 15 min once every $4 \mathrm{~h}$, i.e., six times per day, so that each plate received 2 L per day in total.

Mycorrhizal root colonization. Percentage of root length colonized by mycorrhizal fungi was determined on roots stained in trypan blue (Koske and Gemma, 1989) using the gridline-intersect method (Giovannetti and Mosse, 1980).

Plant $P$ analysis. The $\mathrm{P}$ concentrations of the dried, pulverized shoot and roots material were determined using the molybdo-P-blue method (Murphy and Riley, 1962).

Statistics. Four replications per treatment were used in both experiments. Pots and NFT plates were placed randomly in the growth chamber and the position of the plates was varied each time after replacing the nutrient solution. The Student's $t$ test and one-way analysis of variance were applied to determine differences due to $\mathrm{P}$ concentration in the first experiment and mycorrhizal colonization in the second experiment.

\section{Results}

Roots colonization of mycorrhizal plants in Perlite culture was colonized to approximately $60 \%$ when $10 \mu \mathrm{M}$ P was supplied (Table 1 ). When more $\mathrm{P}$ was supplied, root colonization rates further increased. However, there was no significant difference in root colonization rate between 40 and $80 \mu \mathrm{M} P$ supply (Table 1).

After 5 weeks of colonization in Perlite, the shoot fresh weight of lettuce had increased as P supply increased in the nutrient solution. However, there was no significant difference between 40 and $80 \mu \mathrm{M}$ P supply (Table 1).

After colonization in Perlite for 5 weeks in the second experiment, lettuce was transplanted into NFT culture plates. After four weeks in NFT culture, the total root colonization percent- age remained high (about 85.3\%) compared to the initial percentage root colonized in Perlite. The fungal biomass per culture plate (three plants) was as much as $130 \mathrm{mg}$ of dry weight. Furthermore, external hyphae of AM were well developed in this system. After 4 weeks in this system, we found large amounts of external hyphae surrounding the root (Fig. 1). Better developed root mats were formed in mycorrhizal plants compared to nonmycorrhizal plants due to aggregation with fungal hyphae (Fig. 1). Noninoculated plants showed no colonization in this system.

The shoot dry weights of mycorrhizal and nonmycorrhizal plants grown in the NFT system were significantly different 4 weeks after transplanting into the NFT system (Table 2). Dry weight of mycorrhizal lettuce shoot and root were higher than those of nonmycorrhizal lettuce.

The $\mathrm{P}$ concentrations in roots were also higher in mycorrhizal plants compared to nonmycorrhizal plants (Table 3). However, no significant difference in shoot $\mathrm{P}$ concentration between mycorrhizal and nonmycorrhizal plants was observed.

\section{Discussion}

The results indicate that it would be possible to produce arbuscular mycorrhizal plants with root colonization in a NFT culture system. Therefore, NFT would be one way to mass-produce inoculum and commercially produce mycorrhizal horticultural crop under greenhouse conditions. Growth or P uptake of mycorrhizal plants on NFT culture system was not clearly superior to that of nonmycorrhizal plants (Tables 2 and 3 ). This result was expected because nutrients are delivered to the root surface by the solution flow in NFT culture, so that the additional absorbing surface of the extraradical hyphae is of no benefit to the plant (George, 2000). Nevertheless, the NFT system can be used to raise mycorrhizal plants that may be superior in outplanting success, nutritional composition, or selling price.

In the modified NFT system, the AM fungus

Table 2. Dry weights of nonmycorrhizal (NAM) and mycorrhizal (AM) lettuce plants grown in the NFT system after 5 weeks of precolonization in Perlite. Different letters indicate statistical difference between NAM and AM within one P treatment $(P<0.05$, Student's $t$ test $)$. Data are means of four plates with three plants per plate \pm SE.

\begin{tabular}{lcc}
\hline Dry wt $(\mathrm{g})$ & NAM & AM \\
\hline Shoot & $8.09 \pm 0.49 \mathrm{a}$ & $10.79 \pm 0.15 \mathrm{~b}$ \\
Root & $1.84 \pm 0.16 \mathrm{a}$ & $3.16 \pm 0.27 \mathrm{~b}$ \\
\hline
\end{tabular}

Table 3. P concentrations of nonmycorrhizal (NAM) and mycorrhizal (AM) lettuce plants grown in the NFT system after 5 weeks of precolonization in Perlite. Different letters indicate statistical difference between NAM and AM within one $\mathrm{P}$ treatment $(P<0.05$, Student's $t$ test $)$. Data are means of four plates with three plants per plate \pm SE.

\begin{tabular}{lcc}
\hline Dry wt $\left(\mathrm{mg} \cdot \mathrm{g}^{-1}\right)$ & NAM & AM \\
\hline Shoot & $1.23 \pm 0.13 \mathrm{a}$ & $1.16 \pm 0.05 \mathrm{a}$ \\
Root & $1.48 \pm 0.11 \mathrm{a}$ & $2.22 \pm 0.15 \mathrm{~b}$ \\
\hline
\end{tabular}


G. mosseae (BEG 107) could colonize and develop well with lettuce, high root colonization remained or even slightly increased and, in addition, large amounts of fungal biomass were produced. This offers the potential of determining nutrient concentration directly in external hyphae through plant-fungus interaction. Interestingly, in this system the external hyphae of $G$. mosseae (BEG 107) developed very well and even surrounded the lettuce root to form large mats of hyphae. It could give some advantages to commercial inoculum production not only for inoculum quantity and richness but also inhibition of pathogenic microorganisms occurrence (one possible draw back of NFT). Many researchers reported that once arbuscular mycorrhiza was colonized and established well with host plant, it could give an activation of host plant defense mechanisms against other pathogenic organisms (Azcon-Aguilar and Barea, 1996; Gianinazzi-Pearson et al., 1996; Pozo et al., 1999). However, further study should be made to test the inoculum potential of these hyphae by most probable number (MPN) (Kahn, 1988; Lee et al., 1996) or other techniques (Lesueur et al., 2001) compared to those of other culture systems so as to be qualified as commercial inoculum.

Mosse and Thompson (1984) also found large amounts of external mycelium floating as a gray film on the water surface in a nutrient flow culture system (bean colonized with a G. mosseae isolate). In comparison with our experiments, they supplied nutrient solution continuously at a rate of $1 \mathrm{~L} \cdot \mathrm{min}^{-1}$. However, the intermittent supply of nutrient solution in this study could be helpful for providing adequate aeration while avoiding disturbance of fungal growth. Intermittent nutrient supply also reduces costs for horticultural crop production. Our system provided about $22 \mathrm{~h}$ aeration time.

The $\mathrm{P}$ concentration in the nutrient solution could be an important factor because it could reduce fungal inoculation at high level of supply. Hawkins and George (1997) have reported that modified Knop and Hoagland nutrient solution with $0.9 \mathrm{mM} P$ concentration reduced the colonization rate in hydroponics with Linum usitatissimum colonized with $G$. mosseae. In the present study, $80 \mu \mathrm{M}$ P concentration was selected for the pre colonization of lettuce. In the NFT system, both $80 \mu \mathrm{M}$ (Table 3) and $160 \mu \mathrm{M}$ $\mathrm{P}$ (data not shown) used in nutrient solution did not reduce the root colonization rate. The host plant species may certainly have an effect, but it is possible that the useful range for colonization in NFT is 200 to $1.0 \mathrm{~mm} \mathrm{P}$ concentration.
Using a thin layer glass beads as substrate in this system might be helpful to support plant and fungal growth and additionally to avoid complete drying of the root during the nonwatering period. However, it was somewhat difficult to collect most of the external hyphae from the root and glass beads because the mycorrhizal root had developed well and aggregated tightly to the glass beads together with the external hyphae. So it may be preferable in future experiments to use a membrane bag (30 $\mu \mathrm{m}$ in diameter) to separate root and hyphae for the better collection of hyphae.

A NFT culture system may have some advantages in comparison to other culture system. In aeroponics, wilting of plants is a possibility when the water supply is briefly interrupted by some technical problem. In hydroponics, fungal growth may be inhibited by limited aeration. Therefore, it is suggested that NFT is a better production system compared to aeroponics and hydroponics due to not only for inoculum and mycorrhizal crop production but also for investigating activity of external and elemental composition of fungal hyphae to nutrient uptake.

\section{Literature Cited}

Azcón-Aguilar, C. and J.M. Barea. 1996. Arbuscular mycorrhizas and biological control of soilborne plant pathogens-An overview of the mechanisms involved. Mycorrhiza 6:457-464.

Cooper,A.J. 1975. Crop production in re-circulating nutrient solutions. Sci. Hort. 3:251-258.

Dugassa, D.G., G. Grunewaldt-Stöcker, and F. Schönbeck. 1995. Growth of Glomus intraradices and its effect on linseed (Linum usitatissimum L.) in hydroponics culture. Mycorrhiza 5:279-282.

George, E. 2000. Nutrient uptake. Contributions of arbuscular mycorrhizal fungi to plant mineral nutrition, p. 307-343. In: Y. Kapulnik and D. Douds, Jr. (eds.). Arbuscular mycorrhizas: Physiology and function. Kluwer Acad.Pub., Dordrecht.

Giovannetti, M. and B. Mosse. 1980. An evaluation of techniques for measuring vesicular-arbuscular mycorrhizal infection in roots. New Phytol. 84:489-500.

Gianinazzi-Pearson, V., E. Dumas-Gaudot, A. Gollotte, A. Tahiri-Alaoui, and S. Gianinazzi. 1996. Cellular and molecular defense-related root responses to invasion by arbuscular mycorrhizal fungi. New Phytol. 133:45-57.

Hawkins, H.-J. and E. George. 1997. Hydroponic culture of the mycorrhizal fungus Glomus mosseae with Linum usitatissimum L., Sorghum bicolor L. and Triticum aestivum L. Plant Soil 196:143-149.

Hawkins, H.-J. and E. George. 1998. Substrate-free culture of mycorrhizal plants: Aeroponic, nutri- ent flow and hydroponic culture, p. 809-826. In: A. Varma (eds.). Microbes: For health, wealth and sustainable environment. Malhotra Publ. House, New Delhi.

Hawkins, H.-J., M.D. Cramer, and E. George. 1999. Root respiratory quotient and nitrate uptake in hydroponically grown nonmycorrhizal and mycorrhizal wheat. Mycorrhiza 9:57-60.

Hung, L.-L. and D.M. Sylvia. 1988. Production of vesicular-arbuscular mycorrhizal fungus inoculum in aeroponic culture. Appl. Environ. Microbiol. 54:353-355.

Jarstfer, A.G. and D.M. Sylvia. 1995. Aeroponic culture of VAM fungi, p. 428-441. In: A. Varma and B. Hock (eds.). Mycorrhiza-Structure, function, molecular biology and biotechnology. Springer-Verlag, Berlin, Germany.

Kahn, A.G. 1988. Inoculum density of Glomus mosseae and growth of onion plants in unsterilized bituminous coal spoil. Soil Biol. Biochem. 20:749-753.

Koske, R.E. and J.N. Gemma. 1989. A modified procedure for staining roots to detect VA mycorrhizas. Mycol. Res. 92:486-505.

Lee, K.K, M.V. Reddy, S.P. Wani, and N. Trimurtulu. 1996. Vesicular-arbuscular mycorrhizal fungi in earthworm casts and surrounding soil in relation to soil management of a semi-arid tropicalAlfisol. Appl. Soil Ecol. 3:177-181.

Lesueur D, K. Ingleby, D. Odee, J. Chamberlain, J. Wilson, T. T. Manga, J.-M. Sarrailh, and A. Pottinger. 2001. Improvement of forage production in Calliandra calothyrsus: methodology for the identification of an effective inoculum containing Rhizobium strains and arbuscular mycorrhizal isolates. J. Biotechnol. 91:269-282.

Mohammad, A., A.G. Kahn, and C. Kuec. 2000. Improved aeroponic culture technique for production of inocular of arbuscular mycorrhizal fungi. Mycorrhiza 9:337-339.

Mosse, B. and J.P. Thompson. 1984. Vesicular-arbuscular endomycorrhizal inoculum production. I. Exploratory experiments with beans (Phaseolus vulgaris) in nutrient flow culture. Can. J. Bot. 62:1523-1530.

Murphy, J. and J.P. Riley. 1962. Amodified single solution method for the determination of phosphate in natural waters. Anal. Chem. Acta 27:31-36.

Peuss, H. 1958. Untersuchungen zur Ökologie und Bedeutung der Tabakmycorrhiza. Arch. Mikrobiol. 29:112-142.

Pozo, M.J., C. Azcón-Aguilar, E. Dumas-Gaudot, and J. M. Barea. 1999. B-1,3-glucanase activities in tomato roots inoculated with arbuscular mycorrhizal fungi and-or Phytophthora parasitica and their possible involvement in bioprotection. Plant Sci. 141:149-157.

Sylvia, D.M. and D.H. Hubbel. 1986. Growth and sporulation of vesicular-arbuscular mycorrhizal fungi in aeroponic and membrane systems. Symbiosis 1:259-267.

Winsor, G.W., R.G. Hurd, and D. Price. 1979. Nutrient film technique. Glasshouse Crops. Res. Inst. Grower's Bul. 5. 